\title{
MAGE-specific T cells detected directly ex-vivo correlate with complete remission in metastatic breast cancer patients after sequential immune-endocrine therapy
}

\author{
Maxwell Janosky ${ }^{\dagger}$, Rachel L Sabado ${ }^{\dagger}$, Crystal Cruz, Isabelita Vengco, Farah Hasan, Arthur Winer, Linda Moy \\ and Sylvia Adams*
}

\begin{abstract}
Studies suggest that conventional cancer therapies given after immunotherapy (IT) can boost antitumor immunity and possibly improve response rates and progression-free survival. We report two cases of metastatic breast cancer with durable complete responses (CRs) after sequential IT and endocrine therapy. Immune analyses of these long-term disease-free breast cancer patients previously treated with imiquimod (IMQ) suggest in-situ vaccination is achieved by topical application of the TLR-7 agonist directly onto tumors. Furthermore, IT-induced antigen-specific T cells were expanded by subsequent endocrine therapy and correlated with response, persisting $>2$ years. Our findings therefore suggest that the induction/boosting of polyfunctional tumor antigen-specific $T$ in response to sequential immune endocrine therapy and detected directly ex-vivo can serve as a peripheral blood biomarker for true clinical benefit.
\end{abstract}

\section{Introduction}

Immunotherapy and harnessing anti-tumor immune effects of conventional cancer therapies have great potential for the treatment of several cancers. Evidence is emerging that subtypes of breast cancer can be immunogenic, and that the endogenous as well as the induced anti-tumor immune responses are linked to clinical outcomes in breast cancer [1-6]. However, the field has struggled to define immune monitoring benchmarks for clinical benefit. Several studies suggest that conventional cancer therapies given after immunotherapy, can further boost antitumor immunity and have shown higher than expected response rates and/or progression-free survival [7-12]. We report on two cases of metastatic breast cancer with extensive immune monitoring after an unusually favorable clinical course on sequential immunoendocrine therapy. Two of ten patients treated in a prospective study of topical imiquimod (IMQ), a synthetic imidazoquinoline and Toll-like receptor (TLR)-7 agonist, [13] applied to the

\footnotetext{
* Correspondence: Sylvia.adams@nyumc.org

${ }^{\dagger}$ Equal contributors

NYU Laura and Isaac Perlmutter Cancer Center, New York University School of Medicine, 160 E 34th Street, New York, NY 10016, USA
}

involved skin overlying a large primary breast cancer had a complete and durable clinical response (CR) of all metastatic sites during subsequent therapy. We analyzed the longitudinal anti-tumor immunity in these two patients and demonstrate polyfunctional $\mathrm{T}$ cells specific to tumor and cancer testes $(\mathrm{CT})$ antigens detected directly ex-vivo in the peripheral blood, coinciding with $\mathrm{CR}$, suggesting a possible benchmark of beneficial immune modulation.

\section{Methods \\ Patients}

The prospective single arm study of imiquimod in metastatic breast cancer (clinicaltrials.gov NCT00899574, [13]) to assess response in skin metastasis was approved by the New York University IRB and was amended to collect follow-up blood in study patients. Patients consented to the research and photographs provided in this publication. Ten patients were enrolled and treated. IMQ was applied to cutaneous areas involved by tumor for 8 weeks. While their treated tumors did not regress on study, two patients entered a CR on the next line regimen with the antiestrogen fulvestrant. As CRs to fulvestrant are infrequent (1\% in phase 3 trial) [14] and both are ongoing, we analyzed 
the patients' peripheral blood mononuclear cells (PBMCs) 2 years after enrollment into the IMQ trial. PBMCs were isolated from heparinized blood by Ficoll centrifugation and frozen in aliquots using pooled human serum (90\%) and DMSO (10\%).

\section{Intracellular cytokine analysis of ex-vivo PBMCs}

PBMCs available from pre-IMQ-treatment, post-IMQtreatment, and long-term follow up were thawed, washed in complete R-10 medium supplemented with $20 \mathrm{IU} / \mathrm{ml}$ DNase I (Roche) and cultured overnight at $37^{\circ} \mathrm{C}$. The following day, 5 million viable cells $/ \mathrm{ml}$ were placed in complete R-10 medium in the presence of $1 \mathrm{ug} / \mathrm{ml}$ antiCD28 and anti-CD49d antibodies (BD Biosciences), and either $1 \mathrm{ug} / \mathrm{ml}$ PRAME and MAGE A3 overlapping peptides (Proimmune, $15 \mathrm{mer}$ peptides overlapping by 11 amino acids) or control antigens (ProMix CEF and MOG peptide pool; Prolmmune). A mixture of Brefeldin A and Monensin (GolgiPlug and GolgiStop, BD Biosciences) was added after 1 hour culture, before culturing for an additional 5 hours. Samples were then washed with PBS, stained for 20 minutes at room temperature with antiCD8 PerCP-Cy5.5 and anti-CD4 FITC antibodies (BD Biosciences) and LIVE/DEAD violet (Invitrogen), washed again with PBS, then fixed and permeabilized for $20 \mathrm{mi}-$ nutes at room temperature using Cytofix/Cytoperm solution (BD Biosciences). Samples were then washed using Perm/Wash solution (BD Biosciences) and stained for intracellular antigens using anti-IFN- $\gamma$ AlexaFluor 700 (BioLegend), anti-TNF- $\alpha$ PE-Cy7, anti-IL-2 PE, anti-IL-4 APC, and anti-CD3 APC-H7 (BD Biosciences) antibodies for 20 minutes at room temperature. Samples were washed once with Perm/Wash solution, and acquired on a BD LSR II flow cytometer. 7-color compensation (parallel controls using cells singly stained for each color) and data analysis was performed with Flowjo flow cytometry analysis software (TreeStar). The induction or boosting of TAAspecific $\mathrm{T}$ cell immunity was defined as a post-treatment or long-term follow up value of at least 3-fold higher than baseline that is also 3 -fold or greater than parallel negative controls (and at least 0.03).

Intracellular cytokine staining (ICS) of peripheral lymphocytes after in vitro presensitization (IVS) were performed by thawing PBMCs and culturing overnight in $10 \% \mathrm{PHS} / \mathrm{RPMI}$, followed by separation into CD4+, CD8+, and CD4-CD8- (APC) fractions using Dynal Beads (Invitrogen). Purity of CD4+ and CD8+ fractions were $80-90 \%$ after separation. Each fraction was then washed and resuspended in 5\% PHS/RPMI containing $10 \mathrm{U} / \mathrm{ml} \mathrm{IL}-2$ and $10 \mathrm{ng} / \mathrm{ml} \mathrm{IL-7.} \mathrm{APCs} \mathrm{were} \mathrm{pulsed} \mathrm{with}$ ProMix/ProImmune peptide pool of the desired antigen (MAGE, PRAME, Her2, Survivin, or Wt-1, $5 \mu \mathrm{g} / \mathrm{ml}$ ) for $1 \mathrm{~h}$, irradiated (3000 rads) and then co-cultured with CD4+ or CD8+ cells (ratio of $1: 1$ or 1:2) in a 96-well round-bottom plate for 14-20 days, replenishing medium and cytokines every 2-3 days. After incubation, IVS T cell cultures were tested for reactivity to antigens (e.g. MAGE, PRAME) by ICS. IVS T cell cultures were harvested, washed, and replated in 10\% PHS/RPMI medium in a 96well V-bottom plate. Each test antigen peptide pool $(1 \mu \mathrm{g} /$ $\mathrm{ml}$ ) was added to its own respective test well. Control wells containing DMSO, MOG, CEF, and PMA/Ionomycin were also included. For all ICS cultures, plates were incubated for $1 \mathrm{~h}$ at $37^{\circ} \mathrm{C}$, after which BD GolgiPlug and GolgiStop was added to each well and the cultures incubated another $5 \mathrm{~h}$. Cells were then stained for CD4 and CD8, fixed and permeabilized with BD Cytofix/Cytoperm solution, then washed with $1 \mathrm{X}$ BD Perm/Wash buffer and stained for CD3, CD4, CD8, IL-2, TNF- $\alpha$, IL-4, IFN- $\gamma$ and Live/Dead Violet. Cells were analyzed on a BD LSR II flow cytometer using FACSDiva software. Data were analyzed using FlowJo software (TreeStar).

\section{Results}

Patient 1 is a 49 year old premenopausal woman who presented in September of 2009 at diagnosis with malignant hypercalcemia due to diffuse bone metastases of breast cancer. The primary tumor had replaced the entire left breast and invaded the skin, pectoralis muscle and sternum (Figure 1). Biopsy of the breast revealed a poorly differentiated, estrogen receptor (ER)-positive, human epidermal growth factor receptor (HER)-2 negative invasive ductal carcinoma; imaging tests confirmed widely metastatic disease with pulmonary and osseous metastases. After an initial course of chemotherapy with weekly paclitaxel and bevacizumab (in addition to bisphosphonates) which improved the patient's symptoms, treatment was switched to hormonal therapy with a LH-RH agonist and tamoxifen (with continued zoledronic acid). Upon progression 5 months later (April 2010), topical IMQ was added to all areas of involved skin. After one 8 week cycle the patient showed stable disease locally, however, imaging revealed one new lung metastasis, and the patient discontinued study treatment. Systemic therapy was switched to fulvestrant, on which the patient experienced a CR in September of 2010 including breast, skin, lung and bone lesions, which has been ongoing $>2$ years (follow-up blood draws in February 2012 and April 2012).

Immune monitoring results for patient 1 are shown in Figure 2. Before treatment with imiquimod, no MAGE or PRAME- specific T cells were detected in ex-vivo assays. After IMQ treatment, MAGE-specific T cells were detectable at very low frequency $(0.04 \%$ of $\mathrm{CD} 8+)$, mainly TNF- $\alpha$ secreting. Long-term PBMC evaluation (in the setting of complete clinical response on fulvestrant) revealed a sustained CD8+ T cell response detected directly ex-vivo to MAGE antigens (up to $0.189 \%$ of peripheral CD8+ lymphocytes), with a significant portion producing 


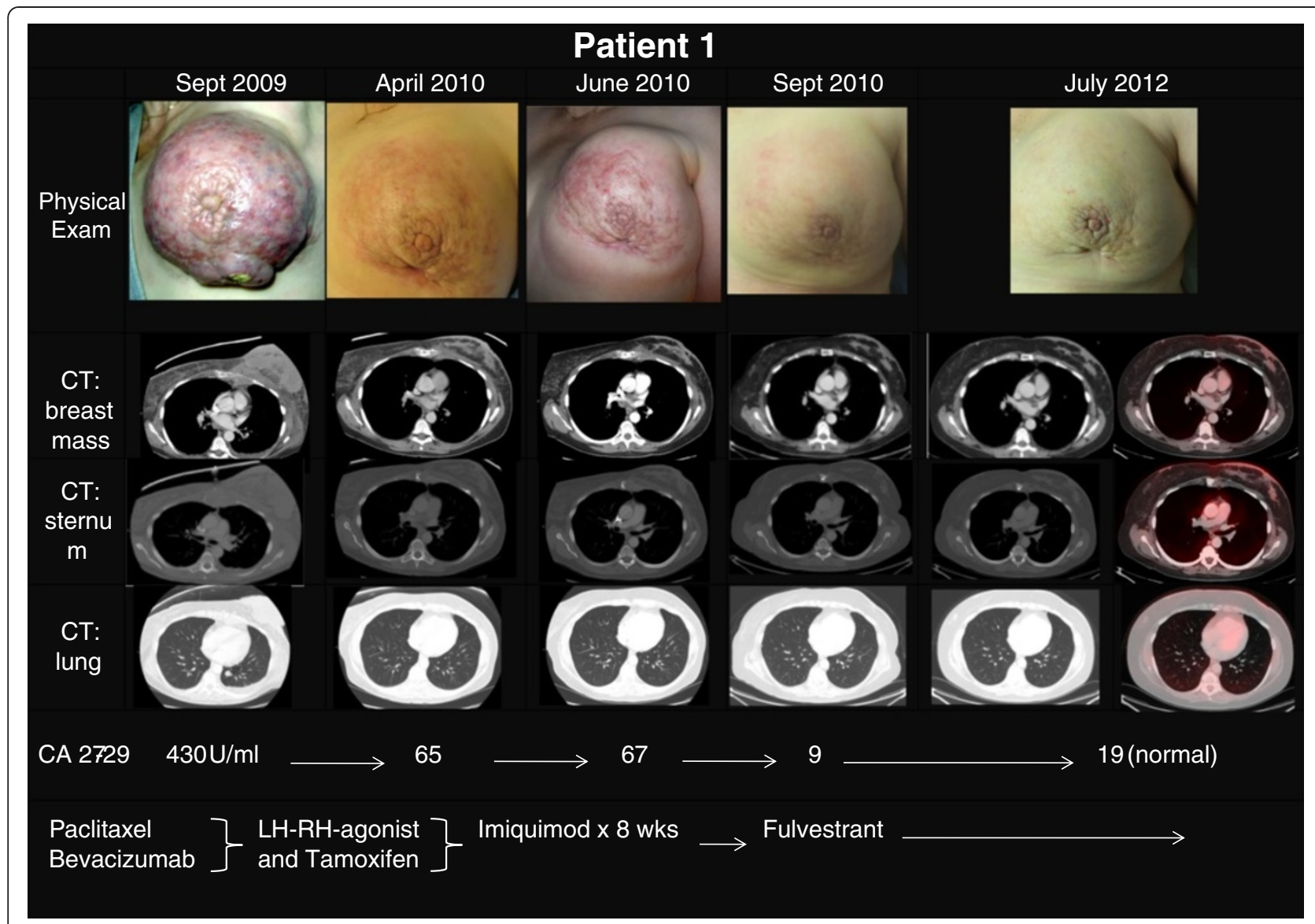

Figure 1 Clinical exam photographs, imaging (CT scans and PET/CT available only at last follow-up), tumor marker (CA 27-29) and treatment regimens according to timeline for patient 1 . At initial presentation of the patient with malignant hypercalcemia in September 2009, the locally advanced breast cancer involved the overlying skin, invaded the pectoralis muscle and sternum; in addition lung metastases were detected by imaging as well as bone metastases (not shown). Interval treatments included paclitaxel, bevacizumab, LH-RH agonist, tamoxifen, topical imiquimod followed by fulvestrant, on which the patient experienced a complete response including breast, skin, lung and bone lesions in September of 2010. At last follow up August 2012, patient had no clinical or radiographic evidence of disease.

both, TNF- $\alpha$ and IFN- $\gamma$ after antigen exposure. After IVS, MAGE-specific T cells showed significant expansion in the CD4+ and CD8+ compartments and confirmed polyfunctionality. MAGE-specific T cells did not secrete IL-4 or IL2 (not shown). A CD8+ T cell response to PRAME was seen ex-vivo at LTFU1, but was only detectable after IVS by LTFU2. Pre-treatment samples were not available for IVS analysis.

Patient 2 is a 50 year old premenopausal woman who presented in August 2009 with a fungating breast mass, involving skin and pectoralis muscle, which was histologically proven to be a poorly differentiated, ER- positive and HER2-positive invasive ductal carcinoma. Imaging demonstrated enlarged axillary and mediastinal lymph nodes as well as adrenal metastases (Figure 3). After initial therapy with trastuzumab and paclitaxel, including a course of concurrent radiotherapy to the breast for local palliation, taxane-induced neurotoxicity developed and treatment was switched to a LH-RH agonist and tamoxifen (with continued trastuzumab). Approximately 4 months later (March 2010), with stable disease, topical IMQ was added to all areas of involved skin. After one 8 week cycle the patient showed stable disease, however, she did not proceed to a second cycle. Upon disease progression 3 months later, systemic treatment was switched to fulvestrant (with continued trastuzumab), and she experienced a CR on this regimen in March of 2011, which has been ongoing $>2$ years. Follow-up bloods were obtained in April 2012.

Immune monitoring results for patient 2 are shown in Figure 4. As there was no functional recovery of PBMC after thawing for the pre- and post-IMQ time points, results are only available from long-term follow-up. MAGE-specific CD4+ $\mathrm{T}$ cells were detected ex-vivo $(0.1 \%)$ during long-term follow-up (in complete clinical remission) (Figure 4B). IVS confirmed the presence of polyfunctional CD4+ MAGE-specific T cells, as well as reactivity to other tumor antigens PRAME, survivin, 


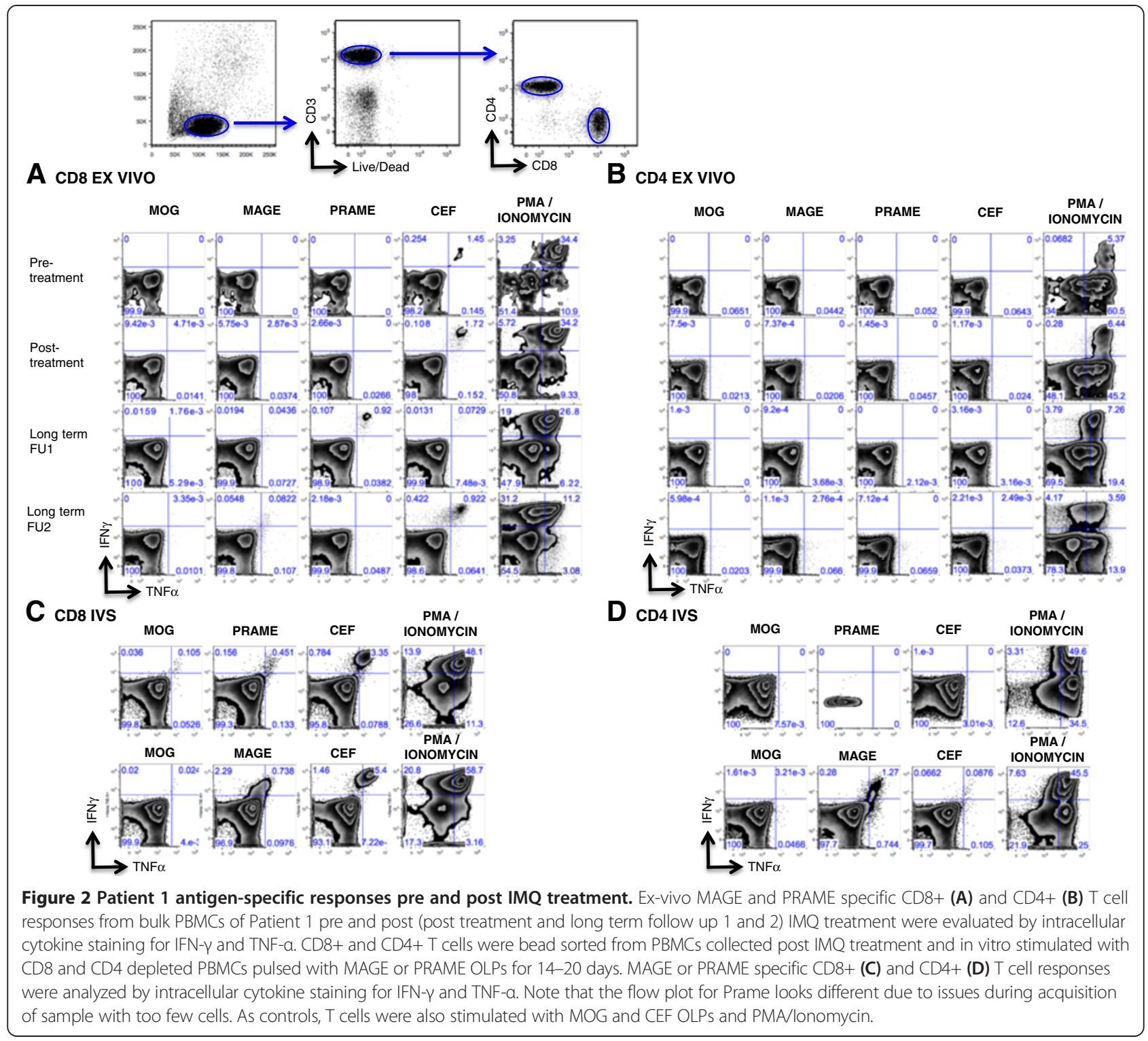

HER2 and Wt1 (not seen or tested for in ex-vivo assays) (Figure 4D). Antigen-specific T cells did not secrete IL-4 or IL-2 (not shown). No MAGE or PRAME specific CD8+ T cells were detected ex-vivo and after in vitro stimulation.

\section{Non-responder patients}

Among the other eight patients who were treated on the IMQ trial, and progressed either on study or during subsequent therapies, three women who consented to follow-up blood draws died due to disease progression. In these three women, no immune response was detected to several tumor antigens including MAGE and PRAME by ex-vivo analysis; results of a representative patient are shown in Figure 5. Only for one of the three patients were paired samples available to additionally analyze the immune response by IVS. No CD4 or CD8 $T$ cell response to MAGE was detected after IVS (data not shown).

\section{Discussion}

We demonstrate that two patients with metastatic breast cancer who were treated with sequential immuneendocrine therapy and experienced durable complete responses had detectable antigen-specific $\mathrm{T}$ cells to several tumor antigens, in particular ex-vivo measurable MAGE A3-specific $T$ cells. Importantly, these antigenspecific T cells were polyfunctional (IFN- $\gamma+$, TNF- $\alpha+$, IL-4-, consistent with a Th1 profile) which has been associated with productive immune responses to vaccines [15]. Parallel evaluation of PBMCs of one patient from before and after IMQ treatment revealed that, while not detectable at 


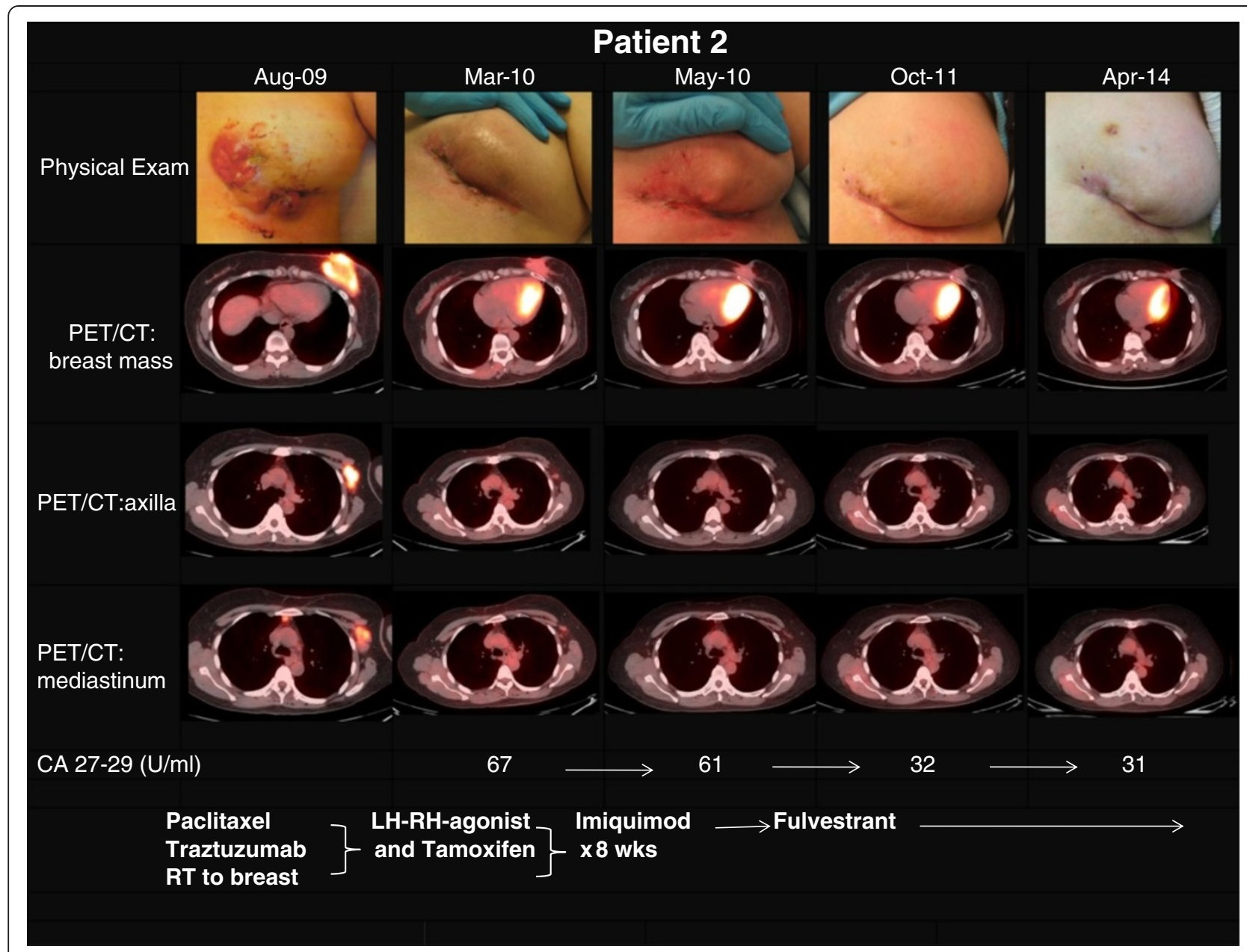

Figure 3 Clinical exam photographs, imaging (PET/CT), tumor marker (CA 27-29) and treatment regimens according to timeline for patient 2. At initial presentation of the patient in August 2009, the locally advanced breast cancer involved the overlying skin, axillary lymph nodes and invaded the pectoralis muscle. In addition an adrenal metastasis and mediastinal lymph nodes were detected by imaging. Interval treatments included paclitaxel, trastuzumab, LH-RH agonist, tamoxifen, topical imiquimod followed by fulvestrant, on which the patient experienced a complete response including breast, lymph nodes and adrenal lesions in October of 2011. At last follow up May 2014, patient had no clinical or radiographic evidence of disease.

baseline, IMQ treatment of the primary tumor involving the skin induced low frequency MAGE-A3-specific CD8+ $\mathrm{T}$ cells which were significantly expanded during subsequent endocrine therapy. In contrast, three patients who died due to subsequent progression did not have detectable MAGE A3-specific T cells.

Although IMQ can induce both CD4 and CD8 T cell responses [16,17], the induction of CD4 versus CD8 T cell responses in these two patients may be partly attributable to the differential effects of prior chemotherapy/ bevacizumab on the function of antigen presenting cells [18] as well as differences in the complex tumor microenvironment [19]. Regardless, both CD4 and CD8 T cell responses are necessary for induction of productive immune response against tumors [20].

Long-term durable responses are rare in metastatic cancer. However, immunotherapy trials followed by chemo- or endocrine therapy have demonstrated in some patients an unexpectedly high response rates and prolonged progression-free survival [7-9]. Patients who respond to immunotherapy or sequential therapies rarely have simultaneous immune monitoring to define the magnitude of immune response boost, correlatives of response and what differentiates the responders from the non-responders, studies which are crucial to the development of more effective therapies. One trial of metastatic breast cancer patients demonstrated an association of the presence of IFN- $\gamma+$ tumor antigenreactive peripheral $\mathrm{T}$ cells with long-term survival after adoptive transfer of antigen-specific $\mathrm{T}$ cells [21]. In this study, even with in vitro reactivation of tumor antigen-specific $\mathrm{T}$ cells derived from patient bone marrow only $1.7 \%$ of PMBCs were antigen specific CD8 cells [22]. Vaccine studies have typically induced lower 


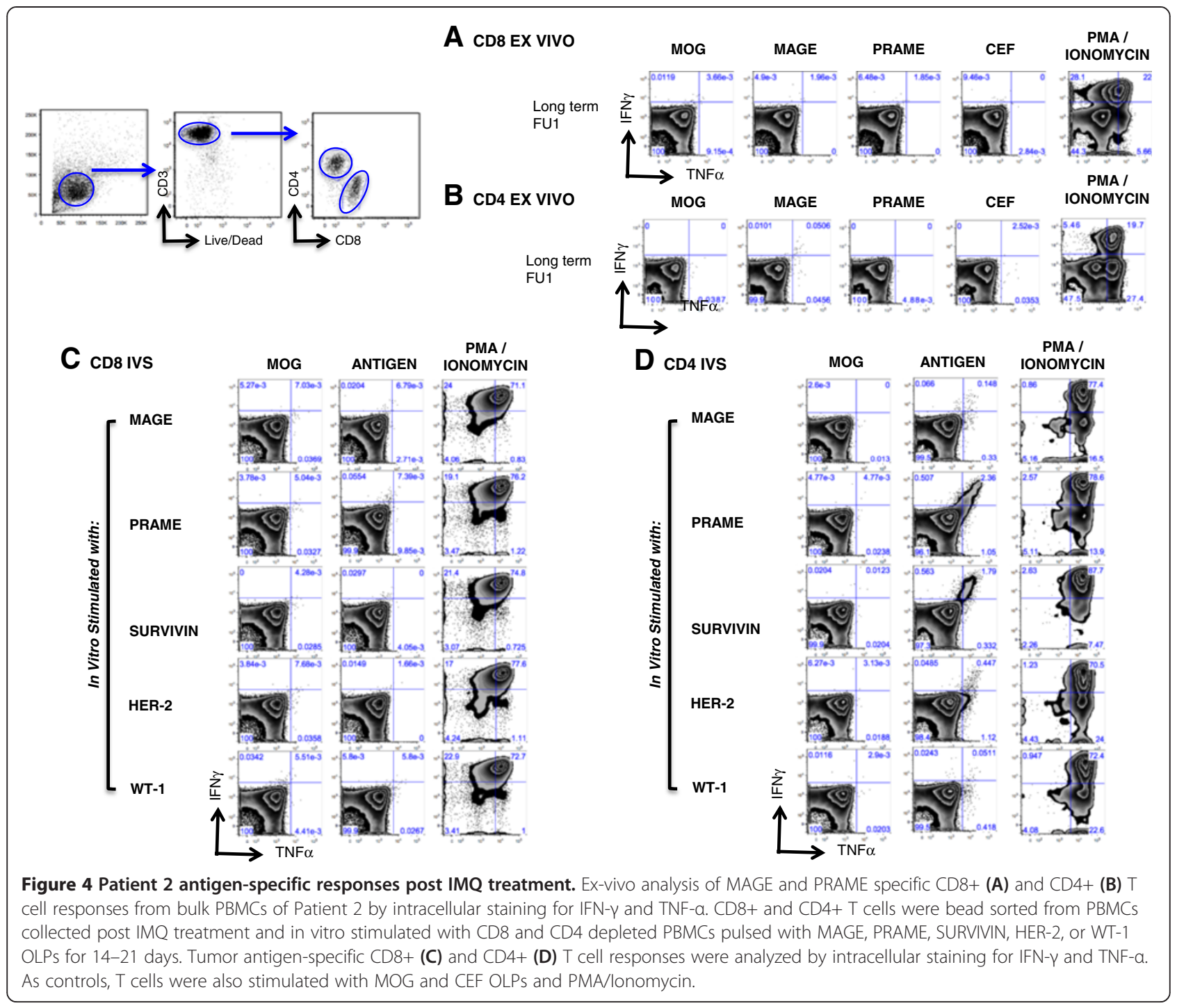

frequencies of antigen-specific T cells. HER2 vaccination with three peptides led to a level of 1 HER2specific $T$ cell to 6,000 PBMCs [23]. In another HER2 vaccine study, at baseline $0.38 \%$ of CD8 cells were HER2-specific. With serial vaccination, the maximum expansion reached $1.8 \%$, but levels returned to $0.45 \%$ at 6 months (not statistically significantly increased from baseline) [24].

In addition to HER2 and PRAME which are expressed in $17 \%$ and $53 \%$ of breast cancers, respectively [25,26], $\mathrm{CT}$ antigens have also been targets for vaccine trials and are desirable antigens due to their restricted expression pattern [27]. Several cancer vaccine trials of CT antigens such as MAGE-A3 and NY-ESO-1 have demonstrated the ability to induce cellular and humoral immune responses, especially when used with potent vaccine adjuvants including TLR agonists [28,29]. The persistence of vaccine-induced $\mathrm{B}$ and $\mathrm{T}$ cell memory responses years after booster immunization has also been demonstrated [28]. Consequently, the National Cancer Institute has placed two CT antigens, MAGE-A3 and NY-ESO-1, into the top 10 category of the Project for the Prioritization of Cancer Antigens [30].

While studies have reported varying frequencies of CT antigen expression in primary breast cancer [31-41], expression data are rarely available for paired samples from the same patient experiencing distant metastases. In melanoma and lung cancer, studies from our group and others reported a higher expression of $\mathrm{CT}$ antigens in metastatic deposits compared with primary lesions, which suggests that these antigens are frequently acquired during progression [42,43]. While robust expression data for breast cancer in primary tumors and subsequent metastases are not available, a study using multiple MAGE-recognizing primers (MMRPs) that can simultaneously detect 6 MAGE-A gene subtypes 


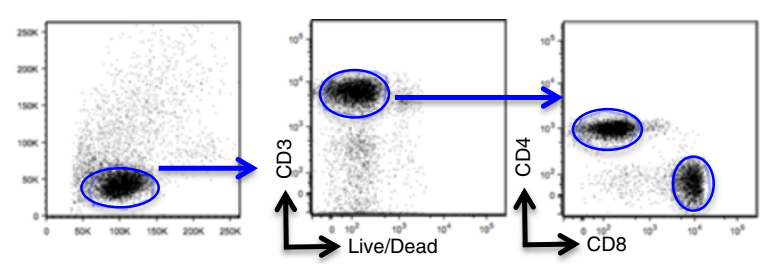

\section{A CD8 EX VIVo}

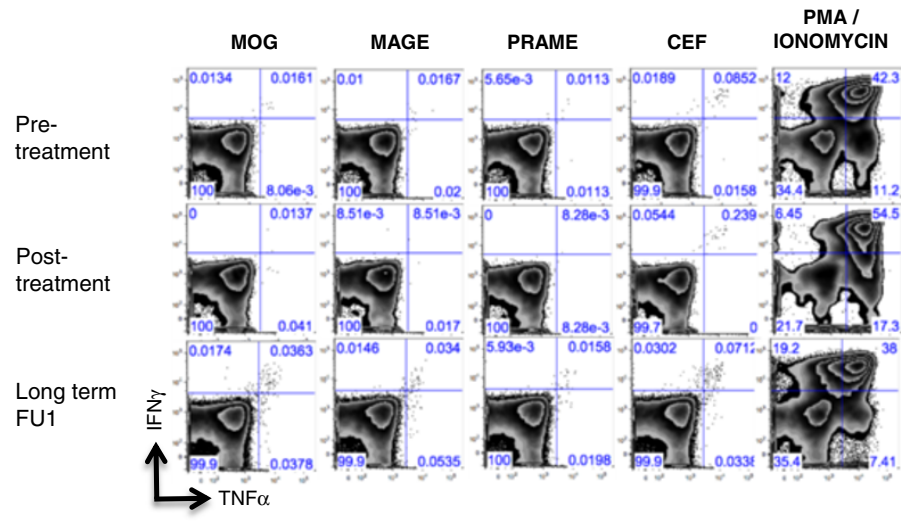

B CD4 EX VIVO

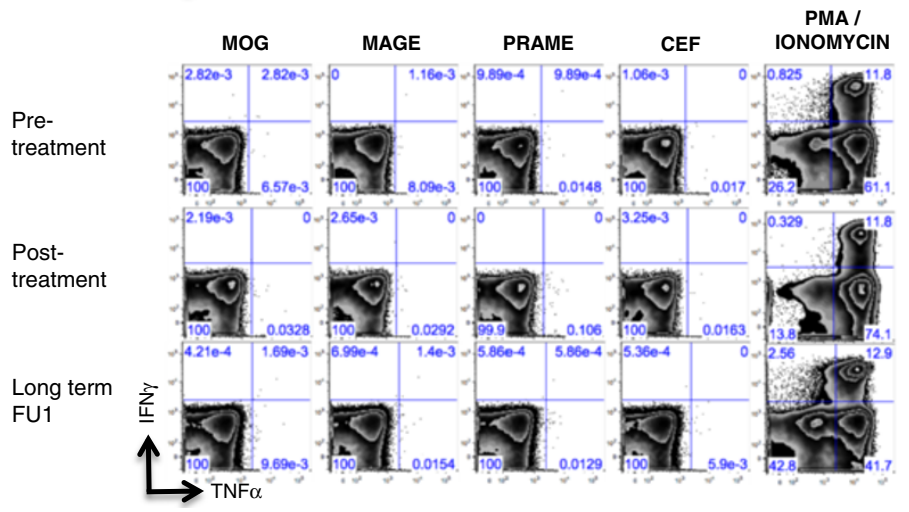

Figure 5 Representative analysis of tumor antigen-specific responses in non-responder patient. Representative ex-vivo analysis of antigen-specific CD8+ (A) and CD4+ (B) T cell responses from bulk PBMCs of one of three patients who also received IMQ treatment alongside Patient 1 and 2 by intracellular staining for IFN- $\gamma$ and TNF-a. As controls, T cells were also stimulated with MOG and CEF overlapping peptides and PMA/lonomycin.

(MAGE-A1-MAGE-A6) expressed by circulating tumor cells in patients with breast cancer suggests that increasing MAGE-A gene expression predicts for tumor progression or recurrence [44].

Our immune evaluation of long-term disease-free breast cancer patients suggests in-situ vaccination is achieved by application of the TLR7- agonist directly onto tumors and subsequent endocrine therapy can expand these responses. Furthermore, we suggest that antigen-specific immune responses detected directly ex-vivo during freedom of detectable disease may indicate a contribution of the immune response to disease control in metastatic breast cancer. This is particularly plausible as the cytokine profile of these cells is similar to $\mathrm{T}$ cells specific to infectious agents including CMV-responsive T cells, and unlike the profile seen in breast cancer where the majority of preexisting cancer antigen T cells fails to produce IFN-y [45].
Strengths of this study include the availability of cryopreserved PBMCs from various time points, which allowed an immune analysis from two breast cancer patients with rare durable responses, and treatment with IMQ on a clinical trial with prospective follow up for 2 years and the willingness of the two long-term responders as well as several patients with disease progression (controls) to donate blood samples. Antigens for immune monitoring were chosen based on their use in vaccine trials and expression in breast cancer. Limitations of our study are that we were unable to test the patients' tumor expression for MAGE and PRAME, although HER2 expression was demonstrated by standard immunohistochemistry in the primary tumor of the patient who developed anti-HER2 $\mathrm{T}$ cell responses. MAGE-A3 antibodies were not detected in any of the patients at any time point (data not shown), HER2 and PRAME antibodies were not measured. Furthermore, 
due to limited samples we could not evaluate the antitumor cytotoxicity of these $\mathrm{T}$ cells in vitro. In addition, the lack of the pre-treatment samples for patient 2 limits the interpretation of our findings.

\section{Conclusion}

In summary, we demonstrate that IT-induced antigenspecific $\mathrm{T}$ cells can be expanded by subsequent endocrine therapy, co-secrete IFN- $\gamma$ and TNF- $\alpha$ and correlated with complete and durable responses. This suggests that the induction and boosting of TAA-specific $\mathrm{T}$ cells detected directly ex-vivo is a benchmark for true clinical benefit in patients with metastatic breast cancer. Therefore, biomarkers in the blood may be appropriate surrogates for predicting clinical responsiveness in the future.

\section{Competing interests}

The authors declare that they have no competing interests.

\section{Authors' contributions}

SA conceived of the study. RS and SA participated in the study design and carried out the analyses. RS, CC, IV, and FH carried out the immunoassays. MJ, RS and SA wrote the manuscript. All authors read and approved the final manuscript.

\section{Acknowledgments}

The work was supported in part by the National Cancer Institute: R01CA161891 (S.A.) and 5P30 CA16087-31 (NYUCI Center Support Grant). We thank all clinical research personnel, regulatory specialist Tiffany Drummond and above all, the participating patients, without whom this work would not have been possible.

Received: 29 June 2014 Accepted: 13 August 2014

Published online: 16 September 2014

\section{References}

1. Aaltomaa S, Lipponen P, Eskelinen M, Kosma VM, Marin S, Alhava E, Syrjanen K: Lymphocyte infiltrates as a prognostic variable in female breast cance. Eur J Cancer 1992, 28A(4-5):859-864.

2. Loi S, Sirtaine N, Piette F, Salgado R, Viale G, Van Eenoo F, Rouas G, Francis P, Crown JP, Hitre E, De Azambuja E, Quinaux E, Di Leo A, Michiels S, Piccart MJ, Sotiriou C: Prognostic and predictive value of tumor-infiltrating lymphocytes in a phase III randomized adjuvant breast cancer trial in node-positive breast cancer comparing the addition of docetaxel to doxorubicin with doxorubicin-based chemotherapy: BIG 02-98. J Clin Oncol 2013, 31(7):860-867.

3. Mahmoud SM, Paish EC, Powe DG, Macmillan RD, Grainge MJ, Lee AH, Ellis 1O, Green AR: Tumor-infiltrating CD8+ lymphocytes predict clinical outcome in breast cancer. J Clin Oncol 2011, 29(15):1949-1955.

4. Muenst S, Soysal SD, Gao F, Obermann EC, Oertli D, Gillanders WE: The presence of programmed death 1 (PD-1)-positive tumor-infiltrating lymphocytes is associated with poor prognosis in human breast cancer. Breast Cancer Res Treat 2013, 139(3):667-676.

5. Demaria S, Pilones KA, Adams S: Cross-talk of breast cancer cells with the immune system. In Breast Cancer - Carcinogenesis, Cell Growth and Signalling Pathways. Edited by Gunduz MGAE. 2011:457-482. InTech.

6. Sylvia A, Gray RJ, Sandra D, Lori G, Perez EA, Shulman LN, Silvana M, Molin W, Jones VE, Saphner TJ, Wolff AC, Wood WC, Davidson NE, Sledge GW, Sparano JA, Badve SS: Prognostic Value of Tumor-Infiltrating Lymphocytes (TILs) in Triple Negative Breast Cancers (TNBC) from two Phase III Randomized Adjuvant Breast Cancer Trials: ECOG 2197 and ECOG 1199. J Clin Oncol 2014, in press.

7. Arlen PM, Gulley JL, Parker C, Skarupa L, Pazdur M, Panicali D, Beetham P, Tsang KY, Grosenbach DW, Feldman J, Steinberg SM, Jones E, Chen C, Marte J, Schlom J, Dahut W: A randomized phase II study of concurrent docetaxel plus vaccine versus vaccine alone in metastatic androgenindependent prostate cance. Clin Cancer Res 2006, 12(4):1260-1269.

8. Chiappori AA, Soliman H, Janssen WE, Antonia SJ, Gabrilovich DI: NGN-225: a dendritic cell-based p53 vaccine (Ad.p53-DC) in small cell lung cancer: observed association between immune response and enhanced chemotherapy effect. Expert Opin Biol Ther 2010, 10(6):983-991.

9. Wheeler CJ, Das A, Liu G, Yu JS, Black KL: Clinical responsiveness of glioblastoma multiforme to chemotherapy after vaccination. Clin Cancer Res 2004, 10(16):5316-5326.

10. Apetoh L, Ghiringhelli F, Tesniere A, Obeid M, Ortiz C, Criollo A, Mignot G, Maiuri MC, Ullrich E, Saulnier P, Yang H, Amigorena S, Ryffel B, Barrat FJ, Saftig P, Levi F, Lidereau R, Nogues C, Mira JP, Chompret A, Joulin V, Clavel-Chapelon F, Bourhis J, Andre F, Delaloge S, Tursz T, Kroemer G, Zitvogel L: Toll-like receptor 4-dependent contribution of the immune system to anticancer chemotherapy and radiotherapy. Nat Med 2007, 13(9):1050-1059

11. Gribben JG, Ryan DP, Boyajian R, Urban RG, Hedley ML, Beach K, Nealon P, Matulonis U, Campos S, Gilligan TD, Richardson PG, Marshall B, Neuberg D, Nadler LM: Unexpected association between induction of immunity to the universal tumor antigen CYP1B1 and response to next therapy. Clin Cancer Res 2005, 11(12):4430-4436.

12. Radfar S, Wang Y, Khong HT: Activated CD4+ T cells dramatically enhance chemotherapeutic tumor responses in vitro and in vivo. J Immunol 2009, 183(10):6800-6807.

13. Adams S, Kozhaya L, Martiniuk F, Meng TC, Chiriboga L, Liebes L, Hochman T, Shuman N, Axelrod D, Speyer J, Novik Y, Tiersten A, Goldberg JD, Formenti SC, Bhardwaj N, Unutmaz D, Demaria S: Topical TLR7 agonist imiquimod can induce immune-mediated rejection of skin metastases in patients with breast cancer. Clin Cancer Res 2012, 18(24):6748-6757.

14. Di Leo A, Jerusalem G, Petruzelka L, Torres R, Bondarenko IN, Khasanov $R$, Verhoeven D, Pedrini JL, Smirnova I, Lichinitser MR, Pendergrass K, Garnett S, Lindemann JP, Sapunar F, Martin M: Results of the CONFIRM phase III trial comparing fulvestrant $250 \mathrm{mg}$ with fulvestrant $500 \mathrm{mg}$ in postmenopausal women with estrogen receptor-positive advanced breast cancer. J Clin Oncol 2010, 28(30):4594-4600.

15. Seder RA, Darrah PA, Roederer M: T-cell quality in memory and protection: implications for vaccine design. Nat Rev Immunol 2008, 8(4):247-258.

16. Adams S, O'Neill DW, Nonaka D, Hardin E, Chiriboga L, Siu K, Cruz CM, Angiulli A, Angiulli F, Ritter E, Holman RM, Shapiro RL, Berman RS, Berner N, Shao Y, Manches O, Pan L, Venhaus RR, Hoffman EW, Jungbluth A, Gnjatic S, Old L, Pavlick AC, Bhardwaj N: Immunization of malignant melanoma patients with full-length NY-ESO-1 protein using TLR7 agonist imiquimod as vaccine adjuvant. J Immunol 2008, 181(1):776-784

17. Soong RS, Song L, Trieu J, Knoff J, He L, Tsai YC, Huh W, Chang YN, Cheng WF, Roden RB, WU TC, Hung CF: Toll like receptor agonist imiquimod facilitates antigen-specific CD8+ T cell accumulation in the genital tract leading to tumor control through interferon-gamma. Clin Cancer Res 2014.

18. Vanneman M, Dranoff G: Combining immunotherapy and targeted therapies in cancer treatment. Nat Rev Cancer 2012, 12(4):237-251.

19. Drake CG, Jaffee E, Pardoll DM: Mechanisms of immune evasion by tumors. Adv Immunol 2006, 90:51-81.

20. Pardoll DM, Topalian SL: The role of CD4+ T cell responses in antitumor immunity. Curr Opin Immunol 1998, 10(5):588-594.

21. Domschke C, Ge Y, Bernhardt I, Schott S, Keim S, Juenger S, Bucur M, Mayer L, Blumenstein M, Rom J, Heil J, Sohn C, Schneeweiss A, Beckhove P, Schuetz F: Long-term survival after adoptive bone marrow T cell therapy of advanced metastasized breast cancer: follow-up analysis of a clinical pilot trial. Cancer Immunol Immunother 2013, 62(6):1053-1060.

22. Schuetz F, Ehlert K, Ge Y, Schneeweiss A, Rom J, Inzkirweli N, Sohn C, Schirrmacher V, Beckhove P: Treatment of advanced metastasized breast cancer with bone marrow-derived tumour-reactive memory T cells: a pilot clinical study. Cancer Immunol Immunother 2009, 58(6):887-900.

23. Knutson KL, Schiffman K, Disis ML: Immunization with a HER-2/neu helper peptide vaccine generates HER-2/neu CD8 T-cell immunity in cancer patients. J Clin Invest 2001, 107(4):477-484.

24. Peoples GE, Holmes JP, Hueman MT, Mittendorf EA, Amin A, Khoo S, Dehqanzada ZA, Gurney JM, Woll MM, Ryan GB, Storrer CE, Craig D, loannides CG, Ponniah S: Combined clinical trial results of a HER2/neu (E75) vaccine for the prevention of recurrence in high-risk breast cancer patients: U.S. Military Cancer Institute Clinical Trials Group Study 1-01 and 1-02. Clin Cancer Res 2008, 14(3):797-803. 
25. Hess KR, Esteva FJ: Effect of HER2 status on distant recurrence in early stage breast cancer. Breast Cancer Res Treat 2013, 137(2):449-455.

26. Doolan P, Clynes M, Kennedy S, Mehta JP, Crown J, O'Driscoll L: Prevalence and prognostic and predictive relevance of PRAME in breast cancer. Breast Cancer Res Treat 2008, 109(2):359-365.

27. Caballero OL, Chen YT: Cancer/testis (CT) antigens: potential targets for immunotherapy. Cancer Sci 2009, 100(11):2014-2021.

28. Atanackovic D, Altorki NK, Cao Y, Ritter E, Ferrara CA, Ritter G, Hoffman EW, Bokemeyer C, Old L, Gnjatic S: Booster vaccination of cancer patients with MAGE-A3 protein reveals long-term immunological memory or tolerance depending on priming. Proc Natl Acad Sci U S A 2008, 105(5):1650-1655.

29. Valmori D, Souleimanian NE, Tosello V, Bhardwaj N, Adams S, O'Neill D, Pavlick A, Escalon JB, Cruz CM, Angiulli A, Angiulli F, Mears G, Vogel SM, Pan L, Jungbluth AA, Hoffmann EW, Venhaus R, Ritter G, Old LJ,

Ayyoub M: Vaccination with NY-ESO-1 protein and CpG in Montanide induces integrated antibody/Th1 responses and CD8 T cells through cross-priming. Proc Natl Acad Sci U S A 2007, 104(21):8947-8952.

30. Cheever MA: Twelve immunotherapy drugs that could cure cancers. Immunol Rev 2008, 222:357-368.

31. Mischo A, Kubuschok B, Ertan K, Preuss KD, Romeike B, Regitz E, Schormann C, De Bruijn D, Wadle A, Neumann F, Schmidt W, Renner C, Pfreundschuh M: Prospective study on the expression of cancer testis genes and antibody responses in 100 consecutive patients with primary breast cancer. Int J Cancer 2006, 118(3):696-703.

32. Otte M, Zafrakas M, Riethdorf $L$, Pichlmeier U, Loning $T$, Janicke F, Pantel K: MAGE-A gene expression pattern in primary breast cancer. Cancer Res 2001, 61(18):6682-6687.

33. Sugita $Y$, Wada $H$, Fujita $S$, Nakata $T$, Sato $S$, Noguchi $Y$, Jungbluth $A A$, Yamaguchi M, Chen YT, Stockert E, Gnjatic S, Williamson B, Scanlan MJ, Ono T, Sakita I, Yasui M, Miyoshi Y, Tamaki Y, Matsuura N, Noguchi S, Old L, Nakayama E, Monden M: NY-ESO-1 expression and immunogenicity in malignant and benign breast tumors. Cancer Res 2004, 64(6):2199-2204.

34. Taylor C, Hershman D, Shah N, Suciu-Foca N, Petrylak DP, Taub R, Vahdat L, Cheng B, Pegram M, Knutson KL, Clynes R: Augmented HER-2 specific immunity during treatment with trastuzumab and chemotherapy. Clin Cancer Res 2007, 13(17):5133-5143.

35. Theurillat JP, Ingold F, Frei C, Zippelius A, Varga Z, Seifert B, Chen YT, Jager $D$, Knuth A, Moch H: NY-ESO-1 protein expression in primary breast carcinoma and metastases: correlation with CD8+ T-cell and CD79a+ plasmacytic/B-cell infiltration. Int J Cancer 2007, 120(11):2411-2417.

36. Jungbluth AA, Antonescu CR, Busam KJ, Iversen K, Kolb D, Coplan K, Chen YT, Stockert E, Ladanyi M, Old L: Monophasic and biphasic synovial sarcomas abundantly express cancer/testis antigen NY-ESO-1 but not MAGE-A1 or CT7. Int J Cancer 2001, 94(2):252-256.

37. Jungbluth AA, Busam KJ, Kolb D, Iversen K, Coplan K, Chen YT, Spagnol GC, Old $\mathrm{L}$ : Expression of MAGE-antigens in normal tissues and cancer. Int $J$ Cancer 2000, 85(4):460-465.

38. Jungbluth AA, Chen YT, Busam KJ, Coplan K, Kolb D, Iversen K, Williamson B, Van Landeghem FK, Stockert E, Old LJ: CT7 (MAGE-C1) antigen expression in normal and neoplastic tissues. Int J Cancer 2002, 99(6):839-845.

39. Grigoriadis A, Caballero OL, Hoek KS, Da Silva L, Chen YT, Shin SJ, Jungbluth AA, Miller LD, Clouston D, Cebon J, Old LJ, Lakhani SR, Simpson AJ, Neville AM: CT-X antigen expression in human breast cancer. Proc Natl Acad Sci U S A 2009, 106(32):13493-13498.

40. Curigliano G, Viale G, Ghioni M, Jungbluth AA, Bagnardi V, Spagnoli GC, Neville AM, Nole F, Rotmensz N, Goldhirsch A: Cancer-testis antigen expression in triple-negative breast cancer. Ann Oncol 2011, 22(1):98-103.

41. Kavalar R, Sarcevic B, Spagnoli GC, Separovic V, Samija M, Terracciano L, Heberer M, Juretic A: Expression of MAGE tumour-associated antigens is inversely correlated with tumour differentiation in invasive ductal breast cancers: an immunohistochemical study. Virchows Arch 2001, 439(2):127131

42. Barrow C, Browning J, MacGregor D, Davis ID, Sturrock S, Jungbluth AA, Cebon J: Tumor antigen expression in melanoma varies according to antigen and stage. Clin Cancer Res 2006, 12 (3 Pt 1):764-771.

43. Velazquez EF, Jungbluth AA, Yancovitz M, Gnjatic S, Adams S, O'Neill D, Zavilevich K, Albukh T, Christos P, Mazumdar M, Pavlick A, Polsky D, Shapiro R, Berman R, Spira J, Busam K, Osman I, Bhardwaj N: Expression of the cancer/testis antigen NY-ESO-1 in primary and metastatic malignant melanoma (MM)-correlation with prognostic factors. Cancer Immun 2007, 7:11.
44. Kwon S, Kang SH, Ro J, Jeon CH, Park JW, Lee ES: The melanoma antigen gene as a surveillance marker for the detection of circulating tumor cells in patients with breast carcinoma. Cancer 2005, 104(2):251-256.

45. Inokuma M, Dela Rosa C, Schmitt C, Haaland P, Siebert J, Petry D, Tang M, Suni MA, Ghanekar SA, Gladding D, Dunne JF, Maino VC, Disis ML, Maecker $H T$ : Functional T cell responses to tumor antigens in breast cancer patients have a distinct phenotype and cytokine signature. I Immunol 2007, 179(4):2627-2633.

doi:10.1186/s40425-014-0032-2

Cite this article as: Janosky et al:: MAGE-specific T cells detected directly ex-vivo correlate with complete remission in metastatic breast cancer patients after sequential immune-endocrine therapy. Journal for ImmunoTherapy of Cancer 2014 2:32.

\section{Submit your next manuscript to BioMed Central and take full advantage of:}

- Convenient online submission

- Thorough peer review

- No space constraints or color figure charges

- Immediate publication on acceptance

- Inclusion in PubMed, CAS, Scopus and Google Scholar

- Research which is freely available for redistribution

Submit your manuscript at www.biomedcentral.com/submit
C Biomed Central 